\title{
Структура и свойства пленок оксида галлия, полученных высокочастотным магнетронным напылением
}

\author{
() В.М. Калыгина, Т.З. Лыгденова, В.А. Новиков, Ю.С. Петрова, А.В. Цымбалов, Т.М. Яскевич \\ Национальный исследовательский Томский государственный университет, \\ 634050 Томск, Россия \\ E-mail: Kalygina@ngs.ru
}

(Получена 26 апреля 2018 г. Принята к печати 1 октября 2018 г.)

\begin{abstract}
Исследованы свойства пленок оксида галлия, полученных высокочастотным магнетронным распылением мишени $\beta-\mathrm{Ga}_{2} \mathrm{O}_{3}$ с осаждением на сапфировую подложку. После нанесения пленки оксида галлия оказываются поликристаллическими, содержат кристаллиты $\alpha$ - и $\beta$-фазы. Воздействие кислородной плазмой не приводит к появлению новых кристаллитов, но в несколько раз увеличивает их средний размер в плоскости подложки. После отжига при $900^{\circ} \mathrm{C}$ размер кристаллитов увеличивается в 2 раза по сравнению с пленкой без отжига. Пленки, не подвергнутые термическому отжигу, обладают большим сопротивлением при $20^{\circ} \mathrm{C}$. В интервале $50-500^{\circ} \mathrm{C}$ проводимость образцов $(G)$ слабо зависит от температуры $T$ и увеличивается по экспоненциальному закону при дальнейшем повышении $T$ с энергией активации $0.7-1.0$ эВ. После отжига пленок в аргоне при $900^{\circ} \mathrm{C}\left(30\right.$ мин) участок резкого роста $G$ начинается при $T \approx 350^{\circ} \mathrm{C}$. На кривой зависимости $\ln G$ от $1 / T$ наблюдается максимум в интервале $470-520^{\circ} \mathrm{C}$, который сменяется участком спада проводимости при более высоких температурах. Необычный вид температурной зависимости проводимости после отжига связан с изменением структуры и фазового состава поликристаллической пленки оксида галлия и, возможно, с эффектами на поверхности. Структуры, полученные на диэлектрической подложке, оказываются солнечно-слепыми в видимом диапазоне длин волн и чувствительными к воздействию излучения в ультрафиолетовом диапазоне (222 нм).
\end{abstract}

DOI: 10.21883/FTP.2019.03.47296.8901

\section{1. Введение}

В зависимости от метода и условий получения тонкие пленки металлооксидных материалов могут быть монокристаллическими, поликристаллическими либо аморфными. Поэтому изучение электрических свойств, оптических характеристик таких пленок в сочетании с их структурой сопряжено со значительными трудностями.

Существует несколько подходов к описанию структуры, фазового состава, поведения дефектов и примесей в оксидных пленках включая $\mathrm{Ga}_{2} \mathrm{O}_{3}$. С этим вопросом тесно связан механизм проводимости моно- и поликристаллических тонких слоев этих материалов. При исследовании оксида галлия, например, особый интерес и дискуссию вызывает влияние кислорода, водорода, марганца и ряда других элементов на электрические, оптические и магнитные свойства пленок. Сложность решения проблемы обусловлена зависимостью свойств пленок от способов получения и последующих технологических процессов. Нередко результаты исследований одних и тех же металлооксидных материалов оказываются противоречивыми.

\section{2. Методика эксперимента}

В данном сообщении обсуждаются результаты исследований пленок оксида галлия, полученных высокочастотным (ВЧ) магнетронным напылением. Пленки толщиной 150-200 нм наносили при магнетронном распылении мишени $\mathrm{Ga}_{2} \mathrm{O}_{3}(99.9999 \%)$ на ненагретые сапфи- ровые подложки на установке AUTO-500 (производитель Edwards) в газовой смеси $\mathrm{Ar} / \mathrm{O}_{2}$. Концентрация кислорода в смеси поддерживалась равной $(56.1 \pm 0.5)$ об\%. Расстояние между мишенью и подложкой составляло 70 мм. Давление в камере во время напыления составляло $7 \cdot 10^{-3}$ мбар.

После нанесения оксида галлия подложку с пленкой делили на три части. Одну часть оставляли без обработки; другую подвергали обработке в кислородной плазме при $50^{\circ} \mathrm{C}$ в течение 20 мин; третью часть отжигали в аргоне 30 мин при температуре $900^{\circ} \mathrm{C}$. Структуру и фазовый состав пленок оксида галлия определяли методом рентгеновского дифракционного анализа (РДА) с использованием установки Lab-X XRD 6000 Shimadzu $\mathrm{X}$-ray diffractometer. Анализ поверхности напыленных пленок проводился с помощью атомно-силового микроскопа „Solver $\mathrm{HV}^{“}$.

\section{3. Результаты и их обсуждение}

Согласно данным рентгеновского дифракционного анализа, пленки, полученные при вышеописанных условиях и не подвергнутые отжигу при высокой температуре, оказываются поликристаллическими, содержат кристаллиты $\alpha$ - и $\beta$-фаз оксида галлия (рис. $1, a$ ).

Атомы кислорода являются необходимым „строительным материалом“ при образовании кристаллитов различных металлооксидных соединений. Концентрация кислорода в пленке растущего окисла определяет его структуру, химический состав, электрические и опти- 

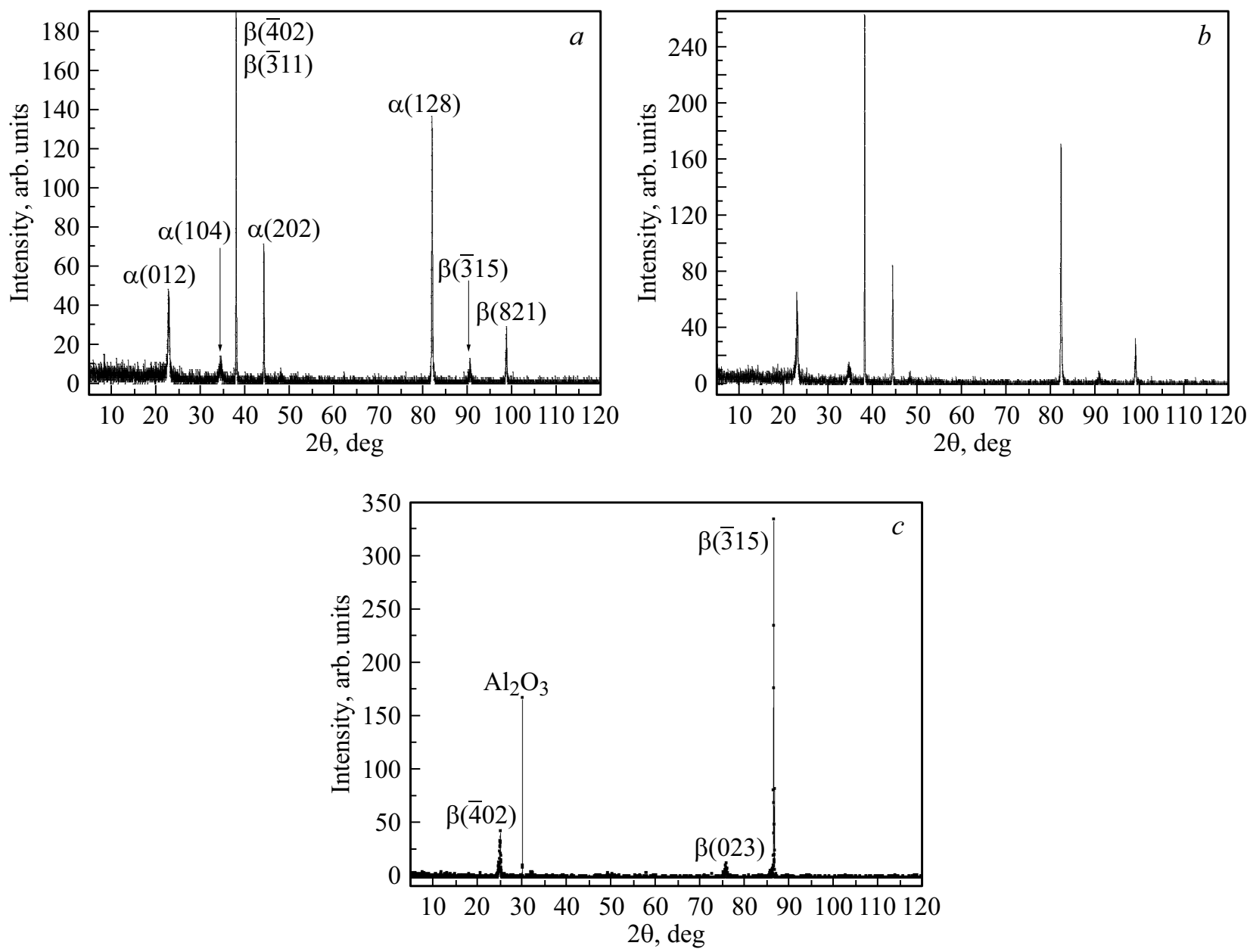

Рис. 1. Спектры РДА пленок оксида галлия: $a-$ без отжига; $b-$ без отжига, но с обработкой в кислородной плазме; $c-$ после отжига в аргоне при $900^{\circ} \mathrm{C}$.

ческие свойства. В связи с этим полученные пленки подвергали обработке в кислородной плазме. Из сопоставления спектров РДА на рис. $1, a$ и $b$ следует, что воздействие кислородной плазмы не приводит к возникновению кристаллитов с новыми ориентациями, наблюдается лишь увеличение в 1.5 раза рефлексов от кристаллитов, сформировавшихся при напылении пленки оксида галлия. Эти результаты отличаются от данных, полученных ранее для пленок, нанесенных термическим испарением порошка $\mathrm{Ga}_{2} \mathrm{O}_{3}$ на сапфировые и полупроводниковые подложки, а также выращенных на эпитаксиальных слоях GaAs методом фотостимулированного анодирования [1,2].

После отжига в аргоне при $900^{\circ} \mathrm{C}$ в течение 30 мин в пленке исчезают кристаллиты $\alpha$-фазы и остаются кристаллиты $\beta$-фазы с разными кристаллографическими плоскостями (рис. 1,c).

Поликристаллическая структура пленок оксида галлия, не подвергнутых каким-либо обработкам, подтверждается данными атомно-силовой микроскопии (АСМ) (рис. 2). Средний размер кристаллитов составляет 40 нм (рис. 2,c).
На рис. 3 приведены двумерные и трехмерные изображения поверхности оксидной пленки без отжига при высокой температуре, но после обработки в кислородной плазме. В результате воздействия кислородной плазмы мелкие кристаллиты объединяются в крупные зерна, размеры которых достигают 200 нм (рис. 3,c).

При латеральном росте кристаллитов после обработки в кислородной плазме их средняя высота снижается с 13.5 до 8 нм.

После отжига в аргоне при $900^{\circ} \mathrm{C}$ оксидная пленка содержит кристаллиты, средний размер которых составляет 90-100 нм (рис. 4).

Измерения электрических и фотоэлектрических характеристик проводили на образцах планарной конструкции (рис. 5). Изготовление образцов включало несколько операций: формирование на сапфировой подложке платиновых электродов и п-образного нагревателя с помощью фотолитографии; напыление пленки $\mathrm{Ga}_{2} \mathrm{O}_{3}$ с последующим отжигом в аргоне при $900^{\circ} \mathrm{C}$; формирование оксидной пленки методом взрывной фотолитографии; резка подложки на отдельные чипы раз-

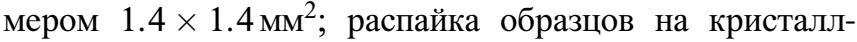



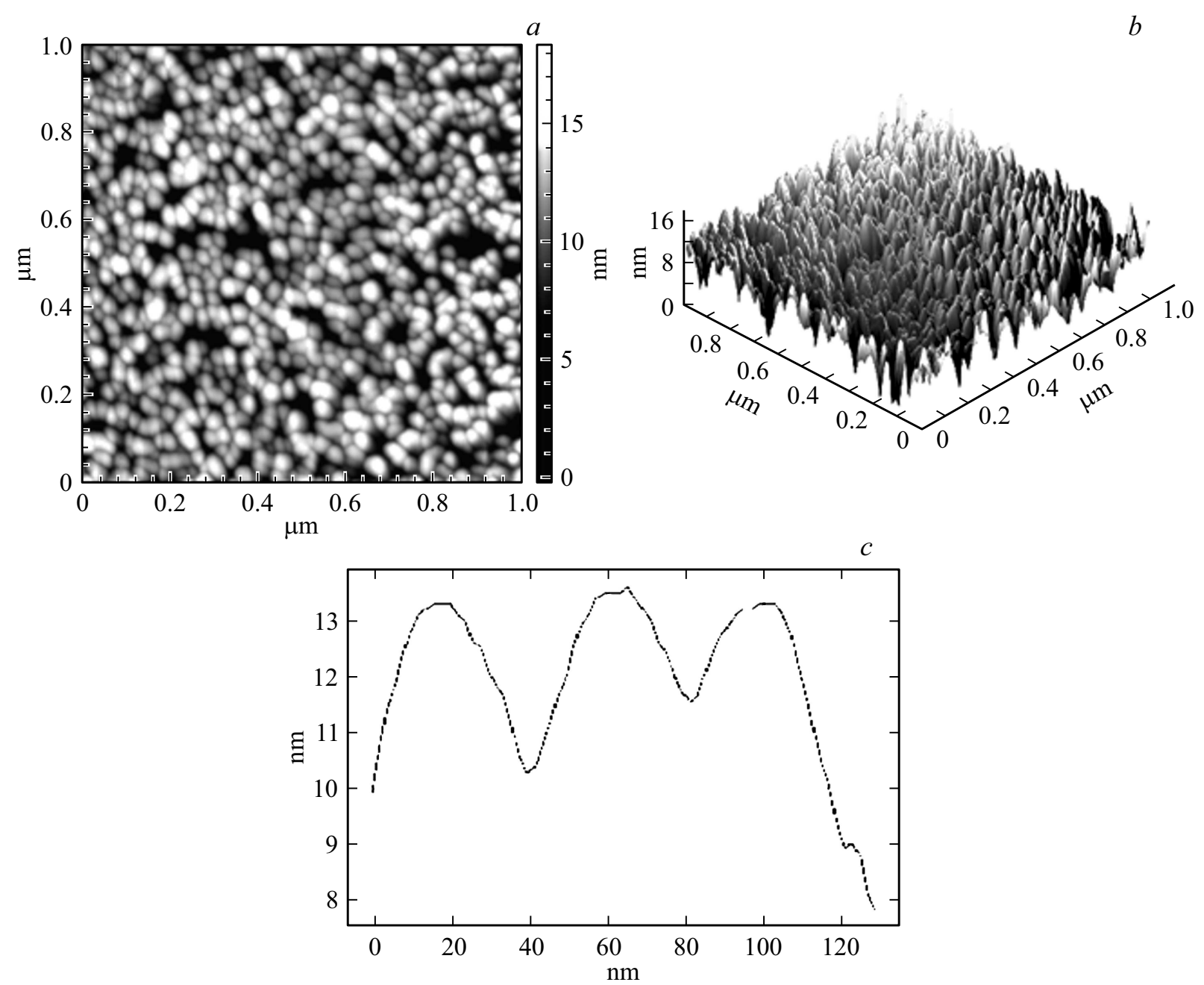

Рис. 2. Поверхность оксидной пленки, не подвергнутой высокотемпературному отжигу и воздействию кислородной плазмы: $a$ - двумерное изображение, $b$ - трехмерное, $c$ - размер кристаллитов (профиль рельефа).

держатель. Схематическое изображение образца приведено на рис. 5. Расстояние между электродами составляло $2.5 \cdot 10^{-2} \mathrm{~cm}$, площадь пленки между электродами $1.56 \cdot 10^{-3} \mathrm{~cm}^{2}$.

Пленки, полученные на сапфировых подложках и не подвергнутые термическому отжигу, обладали сопротивлением $\sim\left(10^{9}-10^{10}\right)$ Ом. Вольт-амперные характеристики (BAX) таких образцов измеряли на автоматизированном комплексе, состоящем из измерительного прибора Keithey 2410 и компьютера. BAX описываются линейной зависимостью тока от напряжения в интервале электрических полей $10^{3}-10^{4} \mathrm{~B} / \mathrm{cm}$.

Температурную зависимость сопротивления образцов в широком интервале температур измеряли на специализированном комплексе, предназначенном для исследований электрических и сенсорных характеристик устройств на основе металлооксидных соединений. Используемая установка позволяла устанавливать и поддерживать заданные температуру и относительную влажность в измерительной камере, в которую одновременно помещали четыре образца. Относительная влажность (RH) в измерительной камере при всех температурах поддерживалась постоянной с помощью специального устройства и в наших экспериментах равнялась $32-34 \%$.

На рис. 6 приведены температурные зависимости проводимости образцов без отжига и после отжига при $900^{\circ} \mathrm{C}$. В интервале $50-500^{\circ} \mathrm{C}$ проводимость образцов $(G)$ слабо зависит от температуры $T$ и увеличивается по экспоненциальному закону при дальнейшем повышении температуры (рис. 6,a). Энергия активации роста проводимости в области высоких температур составляет $0.7-1.0$ эВ.

После отжига пленок оксида галлия в аргоне в течение 30 мин при $900^{\circ} \mathrm{C}$ участок резкого роста проводимости на температурной зависимости $G(1 / T)$ смещается в область более низких температур и начинается при $T \approx 350^{\circ} \mathrm{C}$. Энергия активации увеличения $G \mathrm{c}$ повышением температуры для большей части образцов составляет $0.3-0.5$ эВ. На кривой зависимости $G$ от $1 / T$ наблюдается максимум в интервале $470-520^{\circ} \mathrm{C}$, который сменяется участком спада проводимости при более высоких температурах. 

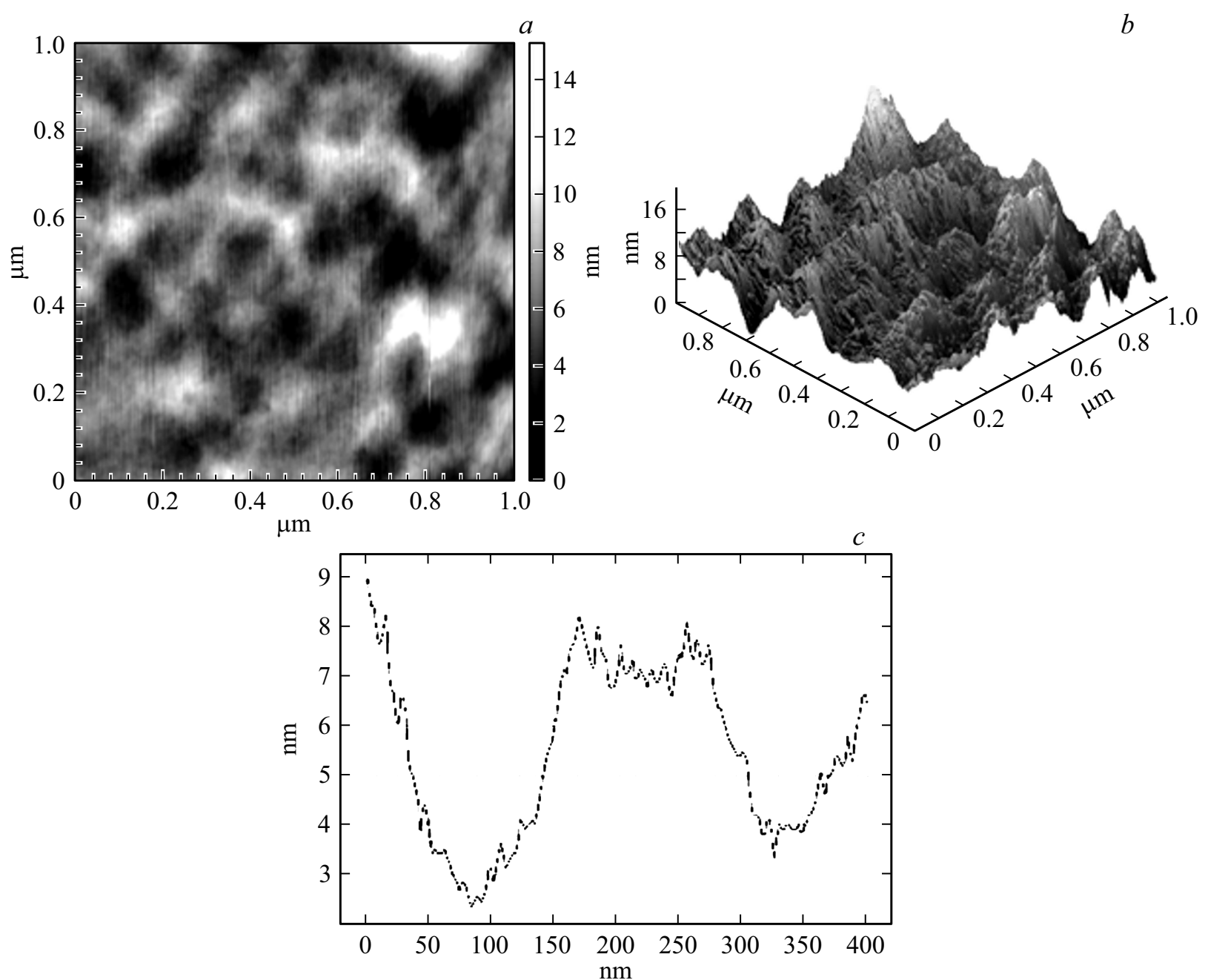

Рис. 3. Поверхность оксидной пленки после воздействия кислородной плазмой: $a-$ двумерное изображение, $b-$ трехмерное, $c$ - размер кристаллитов (профиль рельефа).

Необычный вид температурной зависимости проводимости после отжига при $900^{\circ} \mathrm{C}$ связан с изменением структуры и фазового состава поликристаллической пленки оксида галлия за счет преимущественного появления кристаллитов $\beta$-фазы в пленке оксида галлия (рис. 1,c). Одновременно увеличивается более чем в 2 раза размер кристаллитов по сравнению с пленками без отжига (рис. 2, с и 4,c).

Низкие значения проводимости пленок и ее слабую зависимость от температуры в интервале от комнатной до $350-520^{\circ} \mathrm{C}$ можно объяснить, учитывая высокую концентрацию дефектов и большой вклад ионной составляющей. В этом случае движение электронов в кристалле определяется прыжковым механизмом проводимости (см. вставку на рис. 6, $b$ ) [3,4]. Авторы работы [5] прыжковый механизм проводимости связывают с проводимостью по разупорядоченным границам зерен.

Рост $G$ с повышением температуры как до, так и после отжига, скорее всего, обусловлен активацией электронов, захваченных на глубокие энергетические уровни. Их природа в данной работе не обсуждается.
По аналогии с данными работы [6] снижение проводимости в интервале высоких температур можно объяснить уменьшением подвижности за счет рассеяния носителей заряда на тепловых колебаниях атомов кристаллической решетки. Однако спад проводимости в области высоких температур происходит по экспоненциальному закону, а не по степенному. При постоянной концентрации носителей заряда проводимость должна снижаться $\propto T^{-3 / 2}$.

В поликристаллических пленках, как правило, предполагается существование барьеров на границах квазинейтральных кристаллитов. Барьеры играют ту или иную роль в механизме проводимости пленок в зависимости от способов получения и последующих технологических обработок. Изменение условий на границах зерен может быть одной из возможных причин аномальной температурной зависимости проводимости тонких оксидных пленок. Когда пленка находится в воздушной среде, на поверхности кристаллитов адсорбируются молекулы и атомы кислорода, молекулы воды и гидроксильные группы. 

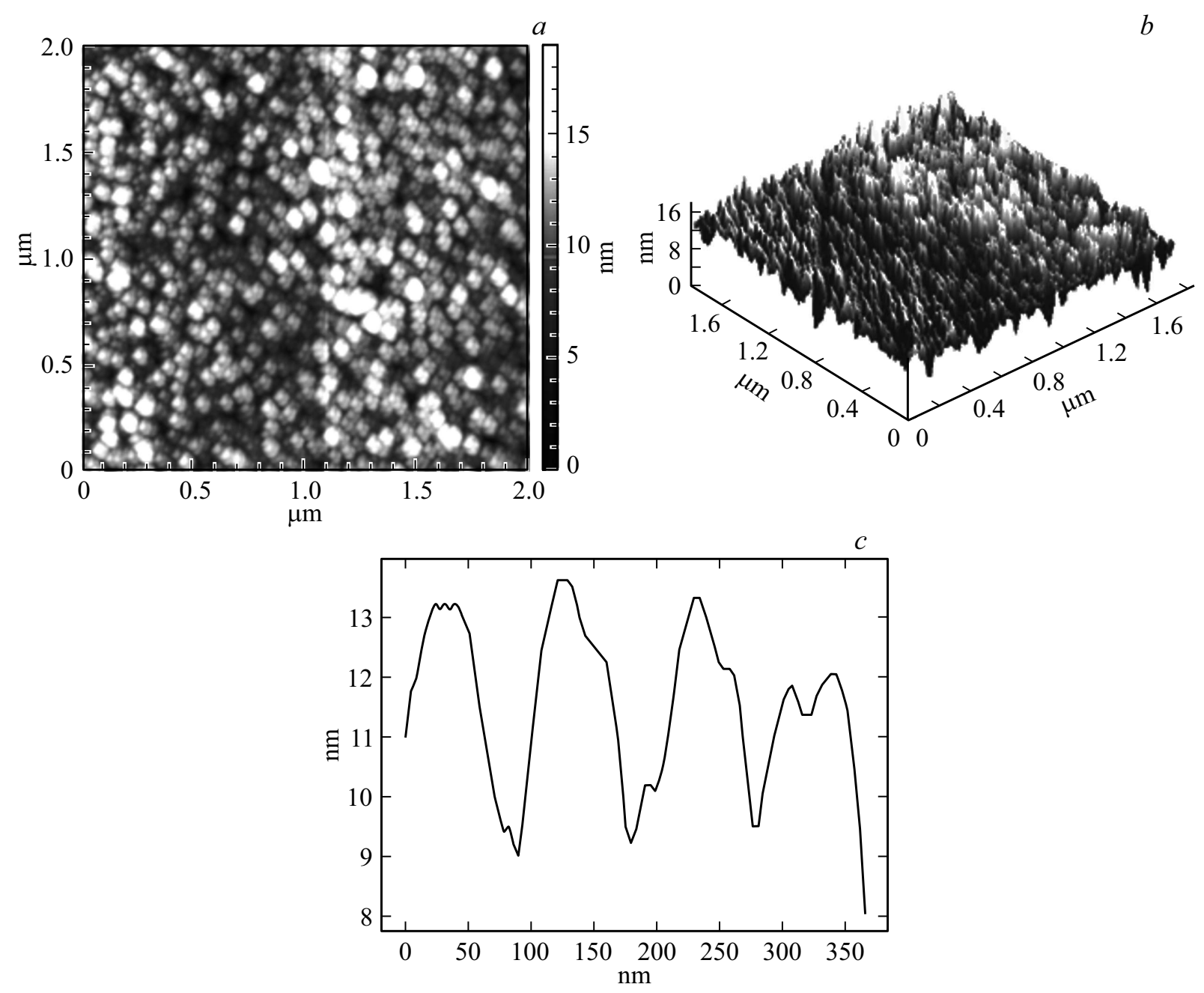

Рис. 4. Поверхность оксидной пленки после отжига при $900^{\circ} \mathrm{C}: a-$ двумерное изображение; $b-$ трехмерное; $c-$ размер кристаллитов (профиль рельефа).

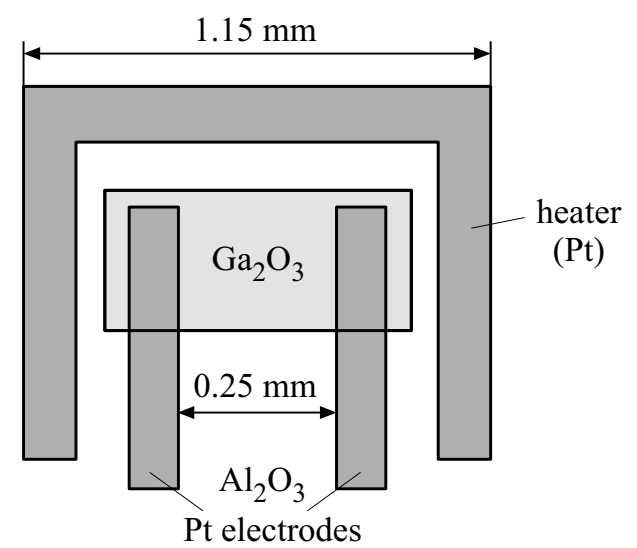

Рис. 5. Схематическое изображение образца.

Согласно работам $[7,8]$, на поверхности $n-\mathrm{Ga}_{2} \mathrm{O}_{3}$ присутствует отрицательный изгиб зон $е \varphi_{s}=0.5$ эВ, где $e-$ заряд электрона, $\varphi_{s}-$ поверхностный потенциал. Значения е $\varphi_{s}$ отсчитываются от энергии дна зоны проводимости на поверхности $E_{c s}$ до $E_{c}$ в объеме пленки. Величина изгиба зон определяется концентрацией доноров $N_{d}$ и плотностью заряда адсорбированных на поверхности ионов $e N_{i}[7,9]$ :

$$
e \varphi_{s}=\frac{\left(e N_{i}\right)^{2}}{2 \varepsilon \varepsilon_{0} N_{d}}+k T
$$

где $\varepsilon$ - диэлектрическая проницаемость оксидной пленки, $\varepsilon_{0}-$ электрическая константа, $k-$ постоянная Больцмана. Отрицательный изгиб зон на поверхности оксида галлия $n$-типа обусловлен как захватом электронов из зоны проводимости в поверхностные состояния на границе пленка/внешняя среда, так и адсорбцией кислорода из окружающей атмосферы. В итоге каждый кристаллит имеет по периферии слой пространственного заряда шириной $d$, проводимость которого значительно меньше проводимости в объеме,

$$
d=\sqrt{2 \varepsilon \varepsilon_{0}\left(e \varphi_{s}-k T\right) / e^{2} N_{d}}
$$

При высокой температуре с поверхности пленки десорбируются молекулы воды, а кислород, адсорбирован- 

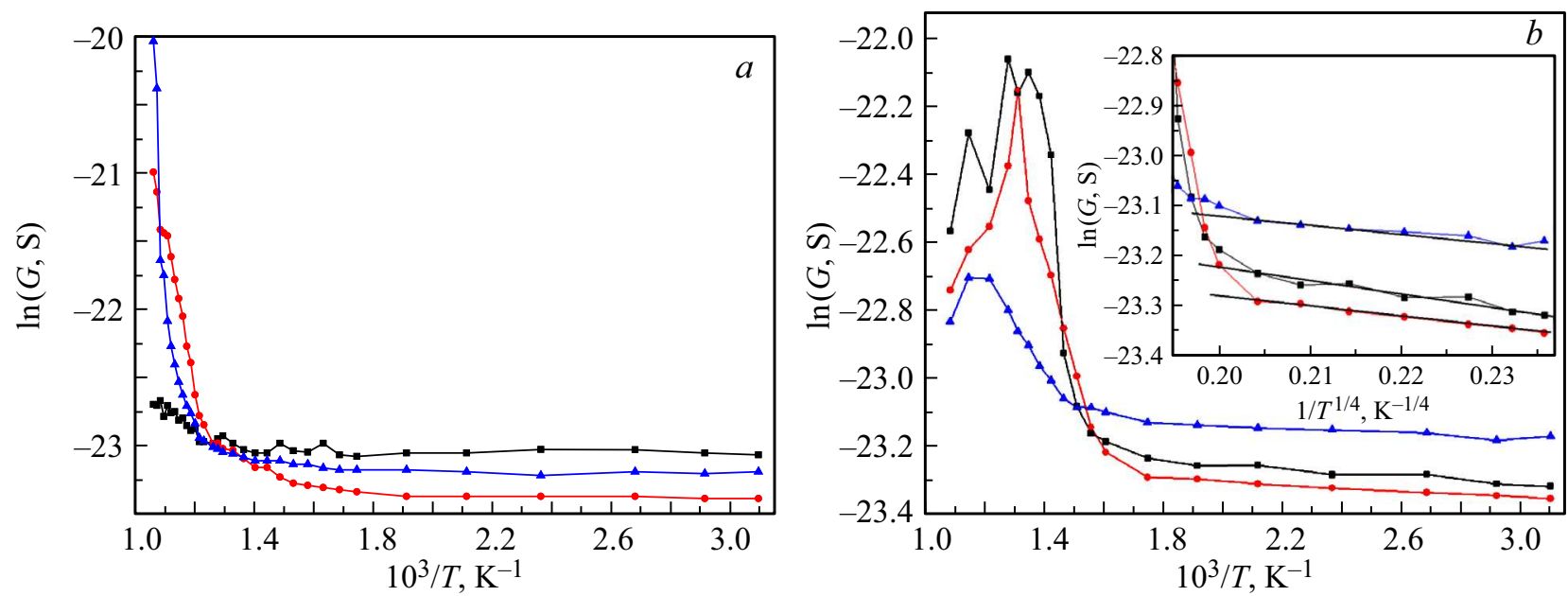

Рис. 6. Температурная зависимость проводимости $G$ пленок оксида галлия на $\mathrm{Al}_{2} \mathrm{O}_{3}$ без отжига $(a)$ и после отжига при $900^{\circ} \mathrm{C}(b)$. На вставке - температурная зависимость проводимости в координатах $\ln G$ от $1 / T^{1 / 4}$.

ный в молекулярной форме $\left(\mathrm{O}_{2}^{-}\right)$при $T \geq 400^{\circ} \mathrm{C}$ переходит в атомарную с образованием ионов $\mathrm{O}^{-}$. В результате увеличивается отрицательный заряд на поверхности, возрастает ширина области пространственного заряда кристаллитов и снижается проводимость пленки.

Возможность объяснения аномальной температурной зависимости пленок оксида галлия с учетом влияния поверхности поддерживается соотношением толщины напыленной пленки и размера зерен кристаллитов после отжига при $900^{\circ} \mathrm{C}$. Аналогичный ход температурной зависимости проводимости наблюдался на пленках оксида олова, полученных на сапфировых подложках ВЧ магнетронным распылением [10].

На рис. 7 приведены вольт-амперные характеристики $I(U)$ образцов планарной конструкции без и при воздействии излучения с длиной волны $\lambda=222$ и 400 нм. Значения темнового тока обозначены как $D$. Из приведенных данных видно, что свет с $\lambda=400$ нм не приводит

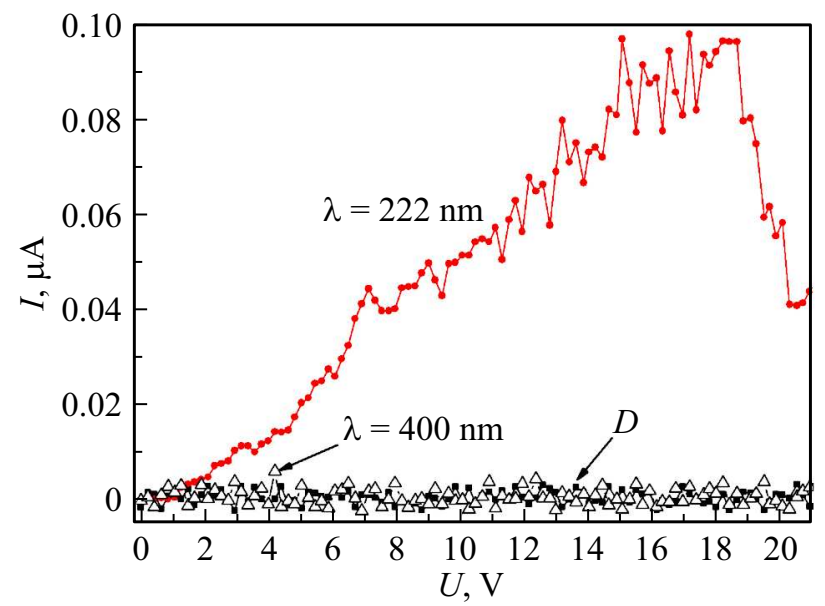

Рис. 7. Вольт-амперные характеристики планарной структуры без воздействия и во время воздействия излучения. Длины волн $\lambda$ указаны. $D-$ темновой ток. к изменению $\mathrm{BAX}$, тогда как излучение с $\lambda=222 \mathrm{Hм}$ вызывает заметный рост тока, который зависит от напряжения на образце. Отсутствие фотоотклика при воздействии света с $\lambda=400$ нм скорее всего связано с тем обстоятельством, что квант энергии этого излучения $h v=3.1$ эВ меньше ширины запрещенной зоны оксида галлия $E_{g}=4.8-4.9$ эВ.

\section{4. Заключение}

Исследованы свойства пленок оксида галлия, нанесенных ВЧ магнетронным распылением мишени $\beta-\mathrm{Ga}_{2} \mathrm{O}_{3}$ на сапфировую подложку. Полученные результаты позволяют сделать следующие выводы:

- после нанесения пленки оксида галлия оказываются поликристаллическими, содержат кристаллиты $\alpha$ - и $\beta$-фазы; воздействие кислородной плазмой не приводит к появлению новых кристаллитов, но в несколько раз увеличивает их средний размер в плоскости подложки;

- отжиг при $900^{\circ} \mathrm{C}$ вызывает изменение поверхности пленки - размер кристаллитов увеличивается в 2 раза по сравнению с пленкой без отжига;

- особенности температурной зависимости проводимости пленок после отжига в аргоне могут быть вызваны влиянием поверхностных эффектов;

- структуры, полученные на диэлектрической подложке, оказываются солнечно-слепыми в видимом диапазоне длин волн и чувствительны к воздействию излучения в ультрафиолетовом диапазоне.

Работа финансировалась за счет грантов РНФ № 18-44-06001 (ТГУ, Россия) и HRSF-0004 (DESY, Германия).

\section{Список литературы}

[1] В.М. Калыгина, А.Н. Зарубин, Е.П. Найден, В.А. Новиков, Ю.С. Петрова, М.С. Скакунов, О.П. Толбанов, А.В. Тяжев, 
Т.М. Яскевич. ФТП, 45 (8), 1130 (2011).

[2] В.М. Калыгина, А.Н. Зарубин, В.А. Новиков, Ю.С. Петрова, О.П. Толбанов, А.В. Тяжев, С.Ю. Цупий, Т.М. Яскевич. ФТП, 47 (5), 598 (2013).

[3] Z. Zhang, E. Farzana, A. Arehart, S.A. Ringel. Appl. Phys. Lett., 108, 052105 (2016).

[4] N.P. Zaretskiy, L.I. Menshikov, A.A. Vasiliev. Sensors Actuators B, 170, 148 (2012).

[5] А.С. Чижов, М.Н. Румянцева, А.М. Гаськов. Неорг. матер., 49 (10), 1078 (2013).

[6] K. Irmscher, Z. Galazka, M. Pietsch, R. Uecer, R. Fornari. J. Appl. Phys., 110, 063720 (2011).

[7] A.M. Armstrong, M.H. Crawford, A. Jayawardena, A. Ahyi, S. Dhar. J. Appl. Phys., 119, 103102 (2016).

[8] T.C. Lovejoy, R. Chen, X. Zheng, E.G. Villora, K. Shimamura, H. Yoshikawa, Y. Yamashita, S. Ueda, K. Kobayashi, S.T. Dunham, F.S. Ohuchi, M.A. Olmstead. Appl. Phys. Lett., 100, 181602 (2012).

[9] В.И. Гаман. Физика полупроводниковых газовых сенсоров (Томск, Изд-во НТЛ, 2012).

[10] Н.К. Максимова, Е.Ю. Севастьянов, Н.В. Сергейченко, Е.В. Черников. Полупроводниковые тонкопленочные газовые сенсоры. (Томск, Изд-во НТЛ, 2016).

Редактор Л.В. Шаронова

\title{
The structure and properties of gallium-oxide films deposited by RF magnetron sputtering
}

\author{
V.M. Kalygina, T.Z. Lygdenova, V.A. Novikov, \\ Yu.S. Petrova, A.V. Tsymbalov, T.M. Yaskevich
}

National Research Tomsk State University, 634050 Tomsk, Russia

Abstract The properties of gallium oxide films prepared by magnetron RF sputtering of $\beta-\mathrm{Ga}_{2} \mathrm{O}_{3}$ with deposition on a sapphire substrate were sudied. As-deposited the gallium oxide films are polycrystalline; the crystallites comprise $\alpha$ - and $\beta$-phase. Exposure to oxigen plasma does not lead to the appearance of new crystallites, but several times increases their average size in the substrate plane. After annealing at $900^{\circ} \mathrm{C}$ crystallite size increases twice as compared with the film without annealing. Films subjected to thermal annealing, had high resistance at $20^{\circ} \mathrm{C}$. In the range of $50-500^{\circ} \mathrm{C}$ conductivity of the samples $(G)$ depends weakly on the temperature $T$, and increases exponentially with further increase of $T$ with an activation energy of $0.7-1.0 \mathrm{eV}$. After annealing the film in $\mathrm{Ar}$ at $900^{\circ} \mathrm{C}(30 \mathrm{~min})$, the sharp rise of $G$ starts at $T \approx 350^{\circ} \mathrm{C}$. On curve $\lg G=(1 / T)$ there is a maximum in the range $470-520^{\circ} \mathrm{C}$ which is replaced by conductivity decrease at higher temperatures. An unusual form of the temperature dependence of conductivity after annealing is associated with a change in the phase composition and structure of the polycrystalline gallium oxide film, and possibly with effects on the surface.

Structures obtained on a dielectric substrate, are solar blind in the visible wavelength range and are sensitive to radiation in the UV range $(222 \mathrm{~nm})$. 